\title{
Impactos da Facilitação de Comércio: evidências do modelo gravitacional
}

\author{
Maurício Jorge Pinto de Souza ${ }^{1}$ \\ Heloisa Lee Burnquist ${ }^{2,3}$
}

Resumo: O presente estudo avalia os efeitos da facilitação de comércio sobre o comércio bilateral de um conjunto de países, que inclui o Brasil e alguns de seus importantes parceiros comerciais. A partir de variáveis associadas à facilitação de comércio, são construídos, para cada país da amostra, três índices de facilitação utilizando a análise fatorial: dois índices de facilitação nas importações e um índice de facilitação nas exportações. A relação desses índices com o padrão de comércio bilateral entre os países é estimada utilizando-se um modelo gravitacional construído com dados de comércio bilateral dos países. Os resultados indicam que o grau de facilitação dos países, seja como importador ou como exportador, é um importante determinante do padrão de comércio internacional.

Palavras-chave: Facilitação de comércio, Análise fatorial, Modelo gravitacional.

\begin{abstract}
This study evaluates the effects of trade facilitation upon bilateral trade pattern between a set of countries including Brazil and some of its major partners. Variables associated to trade facilitation are used to construct three indexes of facilitation for each country of the sample: two indexes of import facilitation and one for facilitating exports. The relation of these indexes with the pattern of bilateral trade is estimated using a gravity model constructed with bilateral trade data within the countries. The results indicate that the degree of facilitation when considering the countries either as importer or exporter is an important determinant of the international trade pattern.
\end{abstract}

Key-words: Trade facilitation, Factor analysis, Gravity model.

Classificação JEL: F13.

\footnotetext{
1 Professor doutor da Fearp/USP. E-mail: mjpsouza@fearp.usp.br

2 Professora associada da Esalq/USP. E-mail: hlburnqu@esalq.usp.br

3 Os autores agradecem ao suporte financeiro do CNPq.
} 


\section{Introdução}

Nos últimos anos, é crescente o reconhecimento de que a liberalização tarifária, embora necessária, não é suficiente para garantir o crescimento do comércio internacional. Outras barreiras não tarifárias (BNTs), procedimentos de fronteira e características do ambiente institucional dos países têm ganhado importância relativa como determinante dos custos de comercialização associados ao comércio internacional. Nesse sentido, a facilitação de comércio entendida como um conjunto de medidas que reduzem os custos para exportar e importar - desponta como um caminho alternativo para reduzir os custos de comercialização internacional e ampliar o comércio exterior.

Em um sentido mais estrito, a definição de facilitação de comércio está associada à redução dos custos referentes aos procedimentos de fronteira, que envolvem, essencialmente, a simplificação e a padronização das formalidades aduaneiras e dos procedimentos administrativos relacionados ao comércio internacional, conhecidos também como elementos de fronteira (border elements). Em um sentido mais amplo, a facilitação de comércio inclui não somente as questões associadas às medidas de fronteira, mas, também, questões que vão além das fronteiras (inside the border issues). Como exemplos, podem ser citadas a qualidade da infraestrutura, a transparência e o ambiente regulatório. Todos esses fatores afetam os custos de comercialização internacional e, consequentemente, os fluxos de comércio (DUVAL, 2006; SADIKOV, 2007).

Na OMC (Organização Mundial do Comércio), a facilitação de comércio tornou-se um tópico de discussão durante a Conferência Ministerial de Cingapura, em dezembro de 1996. Em julho de 2004, os países membros da OMC acordaram em iniciar formalmente as negociações sobre a facilitação de comércio (OMC, 2010). Na Rodada Doha, as negociações sobre facilitação de comércio estiveram focadas na transparência dos regulamentos e procedimentos, na previsibilidade na aplicação de regras, na não discriminação e simplificação dos procedimentos de fronteira (GTN, 2008; ICONE, 2010).

A importância dos custos de comercialização associados ao comércio internacional contribuiu para que estudos e análises empíricas quanto aos efeitos da facilitação de comércio ganhassem importância para a disciplina da economia e do comércio internacional nos últimos anos. As pesquisas empíricas relacionadas a esse tema buscam, de maneira geral, responder a três questões principais: como definir e mensurar a facilitação de comércio? Qual a abordagem metodológica adequada para estimar a importância da facilitação para os fluxos comerciais? E como delinear cenários para simular os efeitos da facilitação de comércio sobre o intercâmbio comercial? (WILSON, MANN e OTSUKI, 2004; PORTUGAL-PEREZ e WILSON, 2010; SOUZA e BURNQUIST, 2011) 
O presente trabalho traz contribuições para as discussões dessas duas primeiras questões, avaliando os efeitos da facilitação de comércio sobre o padrão de comércio bilateral de um conjunto de 43 países, que inclui o Brasil e alguns de seus principais parceiros comerciais. No que se refere à definição e mensuração da facilitação de comércio, o trabalho propõe a construção de índices, através da análise fatorial aplicada a um conjunto de variáveis associadas à definição de facilitação de comércio: no sentido estrito (on-the-border issues) e definição ampliada (inside the border issues). A relação dos índices com o padrão de comércio bilateral é estimada com base na equação gravitacional derivada no modelo de Anderson e van Wincoop $(2003,2004)$ e estimada pelo método Poisson Pseudo-Maximum-Likelihood (PPML), proposto por Silva e Tenreyro (2006). Os resultados são particularmente importantes para o Brasil, pois permitem avaliar de que forma a facilitação tem influenciado o comércio internacional no qual o país está diretamente inserido.

Este trabalho está estruturado em cinco seções, sendo esta introdução a primeira delas. Na sequência é apresentada uma breve revisão de literatura. A seção 3 descreve a metodologia utilizada para mensurar os impactos da facilitação de comércio. A seção 4, destinada aos resultados do trabalho, apresenta os índices de facilitação construídos através da técnica de análise fatorial e contém os resultados das estimativas econométricas do modelo gravitacional. Por fim, a seção 5 apresenta as conclusões.

\section{Estado da Arte: impactos da facilitação de comércio}

No que se refere à mensuração da facilitação de comércio, diferentes abordagens e metodologias têm sido empregadas, tendo predominado, contudo, a construção de indicadores, que captam diferentes aspectos da facilitação de comércio, associados à utilização de estimativas do modelo gravitacional. Podem-se diferenciar os trabalhos em dois grandes grupos: aqueles que avaliam a facilitação de comércio considerando a sua definição mais estrita e os trabalhos que incluem, além de medidas para os procedimentos de fronteira, variáveis associadas à qualidade da infraestrutura, tecnologia da informação e ambiente regulatório.

Pioneiro, o estudo de Wilson, Mann e Otsuki (2003) analisa o impacto da facilitação de comércio sobre o desempenho comercial dos países da Apec (Asia-Pacific Economic Cooperation). Para tanto, os autores utilizam quatro indicadores de facilitação, construídos a partir de dados relacionados à eficiência portuária do país, o ambiente alfandegário, ambiente regulatório e utilização do comércio eletrônico (e-business). O efeito dos indicadores no comércio é avaliado por meio de um modelo gravitacional que inclui, além das variáveis tradicionais, tarifas bilaterais aplicadas. Os autores consideram os fluxos bilaterais de 
produtos manufaturados no período de 1989 a 2000. Os resultados indicam que melhorias na eficiência dos portos, no ambiente alfandegário e na utilização do comércio eletrônico podem ampliar significativamente o comércio.

Na sequência, resultados semelhantes são encontrados por Wilson, Mann e Otsuki (2004). Os autores expandem a análise dos indicadores de facilitação para uma amostra de 75 países e avaliam a relação entre facilitação e o comércio de produtos manufaturados nos anos de 2001 e 2002. Na mesma linha, Shepherd e Wilson (2008) avaliaram os impactos da facilitação sobre o comércio bilateral dos países membros da Associação de Nações do Sudeste Asiático (Asean). Os autores identificaram que o comércio desses países é particularmente influenciado pela infraestrutura de transporte e pela tecnologia de informação.

Utilizando dados de pesquisa aplicada (survey) e estimativas do modelo gravitacional, Apec (2004) avalia o impacto de quatro indicadores de facilitação sobre os fluxos de comércio de 15 economias da Apec, no período de 1988 a 1999. Os resultados evidenciam um efeito positivo e significativo sobre o comércio de melhorias relacionadas aos procedimentos alfandegários $(\mathrm{CP})$, normas e conformidade (SC), mobilidade de negócios (BM) e tecnologia da informação (ICT). Os autores concluem que melhorias simultâneas nas quatro aéreas de facilitação estão associadas a aumentos de comércio intra-Apec superiores ao efeito de uma redução tarifária.

Djankov, Freund e Pham (2006) avaliam a facilitação de comércio, em seu conceito mais estrito, utilizando variáveis associadas a elementos de fronteira. A partir de um modelo gravitacional e de dados de 126 países, os autores demonstraram que o tempo gasto em portos e com a administração aduaneira é um importante determinante dos custos de comercialização e podem impactar significativamente os fluxos comerciais. De acordo com os autores, cada dia adicional de atraso reduz o comércio em pelo menos $1 \%$. Nessa linha, Hummels (2001) examinou a importância do tempo como barreira comercial, utilizando um modelo Probit e dados desagregados do comércio exterior norte-americano. Os resultados de sua análise, com base em dados de 1998, mostram que cada dia adicional necessário para o transporte reduz em $1 \%$ a probabilidade de um país exportar para os Estados Unidos. Considerando-se apenas os produtos manufaturados, esse percentual estimado é de 1,5\%.

Sadikov (2007) estima o modelo gravitacional com dados de 140 países que inclui, além das variáveis tradicionais, o número de documentos exigidos para exportar e o número de procedimentos necessários para o registro de negócios. A primeira variável é utilizada como variável proxy para os elementos de fronteira e a segunda avalia as medidas "dentro da fronteira". Os resultados indicam que, a cada documento adicional exigido para exportar, tem-se uma redução de $4,2 \%$ nas exportações, impacto equivalente a um aumento de $5 \%$ nas tarifas de importação. 
Helble, Shepherd e Wilson (2007) também avaliaram a facilitação de comércio no âmbito das economias da Apec. Os autores utilizam a técnica de componentes principais para construir dois índices, que resumem uma série de indicadores de facilitação. A relação entre os fluxos de comércio e esses índices é estimada por meio de um modelo gravitacional com dados de 2004. Dos resultados, os autores concluem que os potenciais ganhos comerciais para a Apec derivados da promoção da transparência são superiores àqueles estimados mediante uma redução das tarifas bilaterais aplicadas e das barreiras não tarifárias.

Wilson (2009) avalia os efeitos dos procedimentos alfandegários e administrativos no fluxo de comércio bilateral utilizando a metodologia do modelo gravitacional. $\mathrm{O}$ autor inclui no modelo gravitacional, construído com dados de exportação de um grupo de produtos em 2004, as seguintes medidas de facilitação de comércio: o número de documentos necessários para os procedimentos de importação/exportação, número de assinaturas e aprovações necessárias para satisfazer os procedimentos formais e o número de dias necessários para um produto cruzar a fronteira. Os resultados indicam que os procedimentos alfandegários e administrativos têm impacto negativo no comércio bilateral desses produtos.

Souza e Burnquist (2011) avaliam o impacto dos procedimentos de fronteira sobre o padrão de comércio bilateral de um conjunto de países, incluindo o Brasil, com dados de 2003 a 2006. Os autores constroem, para cada país, dois índices aplicados à simplificação de procedimentos de fronteira: um índice de simplificação de procedimentos de exportação e outro para a simplificação de procedimentos de importação. Os resultados das estimativas do modelo gravitacional sugerem que melhorias nas áreas de facilitação de comércio que levariam a um incremento relativo dos índices de simplificação podem estimular os fluxos de comércio entre os países.

O presente trabalho incorpora na análise, além das variáveis associadas aos procedimentos de fronteira, variáveis que caracterizam os elementos denominados "dentro da fronteira", por exemplo, a presença de subornos e barreiras camufladas nas economias. Adicionalmente, o trabalho contribui para as discussões com relação à mensuração da facilitação de comércio ao propor a utilização da técnica multivariada da análise fatorial na construção de índices que sintetizam as informações sobre a facilitação de comércio.

\section{Metodologia}

O enfoque metodológico consiste em propor índices para sintetizar os indicadores de facilitação de comércio, bem como a adequação de procedimentos econométricos para mensurar os impactos da facilitação sobre os fluxos de comércio bilaterais. 


\subsection{Construção dos Índices de Facilitação de Comércio (Análise Fatorial)}

A Tabela 1 apresenta e descreve as fontes das variáveis que são consideradas na construção de índices que sintetizam a facilitação de comércio dos países nas importações e nas exportações. Para a construção desses índices é empregada a análise fatorial.

A análise fatorial é um conjunto de técnicas estatísticas que permite reduzir o número original de variáveis por meio da extração de fatores independentes, de tal forma que esses fatores possam explicar, de forma resumida, as variáveis originais. A análise fatorial pressupõe a existência de um número menor de variáveis não observáveis e subjacentes aos dados, que indicam o que existe de comum nas variáveis originais (PESTANA e GAGEIRO, 2005). Essa abordagem também foi utilizada nos trabalhos de Faria e Burnquist (2006) e Souza e Burnquist (2008), que avaliam a importância das exigências técnicas para as exportações de empresas brasileiras. Almeida, Silva e Lima (2010) examinam os fatores que afetam as decisões políticas brasileiras de emissão de notificações aos acordos SPS e TBT por meio da análise fatorial. Os resultados da análise fatorial são incorporados em um modelo econométrico para explicar o número de notificações emitidas pelo país.

No presente trabalho, a análise fatorial é adotada para construir os índices de facilitação de comércio nas exportações (IFEs) e nas importações (IFIs) para uma amostra de países, a partir das variáveis associadas aos conceitos de facilitação de comércio (elementos de fronteira e elementos "dentro da fronteira"). A opção por considerar Índices de Facilitação de Comércio diferentes para quando o país está na posição de exportador ou importador deve-se ao fato de que alguns podem "facilitar o comércio" para exportar, porém, possuem menor grau de facilitação no que se refere às importações. Os dados apresentados por Souza e Burnquist (2011) mostram que os países, em média, exigem mais documentos para importar do que para exportar. Além disso, de acordo com os autores, o interesse protecionista também parece evidente quanto se observa que os países possuem maior número de agências associadas à importação do que associada aos procedimentos de exportação.

Adicionalmente, vale ressaltar que a utilização dessa técnica facilita a análise econométrica posterior, pois reduz os problemas causados pela forte correlação esperada entre algumas das variáveis. 
Tabela 1. Variáveis relacionadas com os indicadores de facilitação de comércio: descrição e fonte dos dados.

\begin{tabular}{|c|c|c|c|}
\hline Indicador & Variável & Descrição & Fonte \\
\hline $\begin{array}{l}\text { Inexistência de } \\
\text { barreiras comerciais } \\
\text { camufladas }\end{array}$ & BCamufl $_{\mathrm{i}}$ & $\begin{array}{l}\text { Mensura a presença de barreiras } \\
\text { comerciais "camufladas". "In your } \\
\text { country, hidden import barriers (that is, } \\
\text { barriers other than published tariffs and } \\
\text { quotas) are (1 = an important problem, } 7 \\
=\text { not an important problem)?" }\end{array}$ & $\begin{array}{c}\text { Global } \\
\text { Competitiveness } \\
\text { Report (2004) }\end{array}$ \\
\hline $\begin{array}{l}\text { Uso da tecnologia } \\
\text { da informação }\end{array}$ & TecInfor $_{i}$ & $\begin{array}{l}\text { Índice construído para classificar os } \\
\text { países segundo a intensidade com que } \\
\text { o governo do país i utiliza a tecnologia } \\
\text { da informação para fornecer informa- } \\
\text { ções, produtos e serviços. O "E-govern- } \\
\text { mentReadinessIndex" considera também } \\
\text { a infraestrutura das telecomunicações } \\
\text { e o capital humano da economia i. }\end{array}$ & $\begin{array}{l}\text { Nações Unidas } \\
\text { (2008) }\end{array}$ \\
\hline $\begin{array}{l}\text { Importância de } \\
\text { pagamentos } \\
\text { não oficiais }\end{array}$ & PagtoIrreg $_{i}$ & $\begin{array}{l}\text { Mensura a presença e a importância } \\
\text { de pagamentos não oficiais do país i. } \\
\text { In your industry, how commonly would } \\
\text { you estimate that firms make } \\
\text { undocumented extra payments or bribes } \\
\text { connected with import and export permits } \\
\quad(1=\text { common, } 7=\text { never occur }) ?\end{array}$ & $\begin{array}{l}\text { Global } \\
\text { Competitiveness } \\
\text { Report (2004) }\end{array}$ \\
\hline $\begin{array}{l}\text { Ausência de } \\
\text { favoritismo nas } \\
\text { decisões } \\
\text { administrativas }\end{array}$ & Favorit $_{\mathrm{i}}$ & $\begin{array}{l}\text { Mensura a presença de favoritismo } \\
\text { nas decisões administrativas dos } \\
\text { governos da economia. When deciding } \\
\text { policies and contracts, government officials } \\
(1=\text { usually favor well-connected firms } \\
\text { and individuals, } 7=\text { are neutral among } \\
\text { firms and individuals)? }\end{array}$ & $\begin{array}{l}\text { Global } \\
\text { Competitiveness } \\
\text { Report (2004) }\end{array}$ \\
\hline $\begin{array}{l}\text { Desburocratização dos } \\
\text { documentos exigidos } \\
\text { para importação/ } \\
\text { exportação }\end{array}$ & $\begin{array}{l}\text { DocExigExp }_{i} \\
\text { DocExigImp }_{i}\end{array}$ & $\begin{array}{l}\text { Número médio de documentos } \\
\text { necessários para importar ou } \\
\text { exportar no país i }\end{array}$ & $\begin{array}{l}\text { Doing } \\
\text { Business } \\
(2008)\end{array}$ \\
\hline $\begin{array}{l}\text { Número de agências } \\
\text { de fronteira }\end{array}$ & $\begin{array}{l}\text { NumAgenExp }_{i} \\
\text { NumAgenImp }_{i}\end{array}$ & $\begin{array}{l}\text { Número médio de agências } \\
\text { envolvidas com exportação ou } \\
\text { importação do país i }\end{array}$ & $\begin{array}{l}\text { Logistics } \\
\text { Performance } \\
\text { Index } \\
(2007) \\
\end{array}$ \\
\hline $\begin{array}{l}\text { Tempo de } \\
\text { desembaraço } \\
\text { alfandegário }\end{array}$ & TempoDesemb & $\begin{array}{l}\text { Tempo de desembaraço } \\
\text { alfandegário no país i }\end{array}$ & $\begin{array}{l}\text { Logistics } \\
\text { Performance } \\
\text { Index } \\
(2007) \\
\end{array}$ \\
\hline $\begin{array}{l}\text { Previsibilidade do } \\
\text { nível de pagamentos } \\
\text { não oficiais }\end{array}$ & DPPagtoIrreg $_{i}$ & $\begin{array}{l}\text { Desvio padrão da medida que } \\
\text { mensura a presença de pagamentos } \\
\text { não oficiais do país i (PagtoIrreg). } \\
\text { Proxy para a previsibilidade } \\
\text { desse tipo de pagamento. }\end{array}$ & $\begin{array}{l}\text { Global } \\
\text { Competitiveness } \\
\text { Report (2004) }\end{array}$ \\
\hline
\end{tabular}

Fonte: Elaborado pelos autores. 
De acordo com Johnson e Wichern (1998), o modelo fatorial para a i-ésima variável pode ser expresso algebricamente da seguinte forma:

$$
Y_{i}-\mu_{i}=l_{i 1} F_{1}+l_{i 2} F_{2}+\ldots+l_{i m} F_{m}+\varepsilon_{i}
$$

sendo que: $\mu_{\mathrm{i}}$ é a média da variável $i ; \mathrm{F}_{\mathrm{j}}$ representa os j-ésimo fator comum não correlacionado com média zero e variância unitária; $j=1$ até $m$; $1_{i j}$ é a carga fatorial da i-ésima variável no j-ésimo fator e $\varepsilon_{\mathrm{i}}$ é o termo de erro, com média zero, que capta a variação específica em $Y_{i}$ não explicada pelos fatores comuns. $\mathrm{O}$ modelo fatorial implica a seguinte estrutura de covariâncias para a i-ésima variável:

$$
\begin{aligned}
& \operatorname{Cov}\left(Y_{i}, Y_{k}\right) l_{i 1} l_{k 1}+\ldots+l_{i m} l_{k m} \\
& \operatorname{Var}\left(Y_{i}\right)=l_{i 1}^{2}+l_{i 2}^{2}+\ldots+l_{i m}^{2}+\psi_{i} \\
& \operatorname{Cov}\left(Y_{i}, F_{j}\right)=l_{i j}
\end{aligned}
$$

em que:a porção $\left(l_{i 1}+l_{i 2} \ldots+l_{i m}\right)$ explicada pelos $m$ fatores comuns é chamada de i-ésima comunalidade e a porção $\Psi_{i}$ é chamada variância específica.

Para estimar as cargas fatoriais emprega-se o método dos componentes principais e a rotação ortogonal é realizada pelo método Varimax. Para se verificar a adequação do modelo de análise fatorial, utiliza-se a estatística de Kaiser-Meyer-Olkin (KMO) e o teste de esfericidade de Bartlett. A consistência interna dos fatores é avaliada utilizando o teste alpha de Crobach. Se os fatores possuírem uma consistência interna adequada, eles podem ser utilizados para criar índices que sintetizam a informação dada pelos itens que os integram. Esses índices podem ser calculados como médias das variáveis que têm maior peso dentro de cada fator (PESTANA e GAGEIRO, 2005).

Pestana e Gageiro (2005) sugerem que, antes da realização da análise fatorial, se as variáveis forem medidas em escalas diferentes, elas devem ser padronizadas e representadas na mesma direção. Para a construção das variáveis padronizadas, foi subtraído de cada observação o valor médio da variável e, posteriormente, o resultado foi dividido pelo seu desvio padrão. Além disso, de forma a garantir que valores elevados dos índices, construídos com analise fatorial, indiquem maior facilitação, após a padronização foram alteradas as escalas das seguintes variáveis 4 : TempoDesemb, NumAgenExp, NumAgenImp e DocExigImp.

4 Por exemplo, aqueles países que possuem TempoDesemb positivo após a padronização tiveram seu sinal trocado para indicar menor facilitação. Da mesma forma, os países que apresentaram sinal negativo após a padronização tiveram o sinal trocado para indicar maior facilitação. 
Como as variáveis consideradas na construção dos índices estão padronizadas, o resultado do índice é adimensional, sendo que valores negativos indicam menor facilitação relativa, enquanto valores positivos indicam maior facilitação relativa. Para facilitar a interpretação dos resultados, além de facilitar a análise econométrica, cria-se uma escala para os índices, de tal maneira que 0 representa a menor facilitação de comércio e 1 representa a maior facilitação. Para realizar essa modificação, o valor mínimo da amostra é subtraído de cada observação e o resultado é dividido pela amplitude. Dessa forma, assegura-se que o país com menor índice de facilitação de comércio assume valor 0 , enquanto o país com índice mais elevado assume valor 1.

\subsection{O Modelo Gravitacional}

\subsubsection{Modelo Teórico}

O modelo gravitacional aplicado à economia internacional foi introduzido por Tinbergen (1962). Seu nome guarda uma analogia com a lei da gravidade da Física: da mesma forma que a atração entre dois corpos é proporcional a suas massas e reduz com a distância, o fluxo de comércio entre dois países é proporcional a suas rendas e diminui com a distância geográfica (CHENG e WALL, 2005; BALDWIN e TAGLIONI, 2006; SOUZA e BURNQUIST, 2011).

A análise conduzida no presente trabalho adota como referencial teórico o modelo desenvolvido por Anderson e Van Wincoop $(2003,2004)$, no qual o modelo gravitacional é derivado a partir de uma função utilidade do tipo elasticidade de substituição constante (CES), sujeita a uma restrição orçamentária, associada com condições de equilíbrio de mercado. $\mathrm{O}$ modelo permite explicar as exportações realizadas entre o país $i$ e o país $j$, referentes a um determinado setor $k$, em um período de tempo $t$, que assume a seguinte forma:

$$
X_{i j}^{k}=\frac{E_{j}^{k} Y_{i}^{k}}{Y^{k}}\left(\frac{t_{i j}^{k}}{P_{j}^{k} \prod_{i}^{k}}\right)^{1-\sigma_{k}}
$$

em que $Y_{i}^{k}$ e $Y^{k}$ são, respectivamente, a produção do país $i$ e a produção agregada (mundial) no setor $k$; $E_{j}^{k}$ é o dispêndio do país $j$ com o grupo de produtos $k$; $\sigma_{k}$ é a elasticidade de substituição entre grupos de produtos; $t_{i j}^{k}$ representa os custos de comércio incorridos pelos exportadores do setor $k$, no sentido do país $i$ para o país j. Os índices $P_{j}^{k}$ e $\prod_{i}^{k}$ representam índices de preços, sendo também identificados como índices de resistência multilateral ao comércio ${ }^{5}$. Esses índices são introduzidos para indicar que os fluxos de comércio bilateral não dependem

5 Para a derivação completa do modelo teórico, ver Anderson e Van Wincoop (2003, 2004) e Souza (2009). 
somente dos custos de comércio existentes entre os dois países, mas também dos custos de comércio com os demais parceiros comerciais.

No que se refere aos custos de comercialização, o desenvolvimento teórico de Anderson e Van Wincoop $(2003,2004)$ propõe que $t_{i j}^{k}$ seja uma função log-linear de variáveis observáveis, tais como a distância bilateral e outros fatores relacionados às barreiras comerciais entre as duas economias.

\subsubsection{Estratégia Empírica}

Para o presente estudo algumas considerações devem ser feitas sobre a adequação da abordagem teórica descrita anteriormente e a tratabilidade empírica do modelo gravitacional.

Primeira consideração: o modelo Anderson e Van Wincoop $(2003,2004)$ pode ter um tratamento econométrico adequado empregando-se o método de Efeitos Fixos (EF) (ANDERSON e VAN WINCOOP, 2003; FEENSTRA, 2004; FRATIANNI, 2007). Os efeitos fixos permitem controlar a heterogeneidade dos países, efeito de variáveis omitidas não observáveis ou difíceis de mensurar (como os índices de resistência multilateral) (CHENG, WALL, 2005; WILSON, MANN e OTSUKI, 2004; SOUZA, BURNQUIST, 2011). Seguindo Cheng e Wall (2005), Porto e Canuto (2004) e Helble, Shepherd e Wilson (2007), o presente estudo estima o modelo gravitacional considerando-se os efeitos fixos bilaterais. A utilização de efeitos fixos nos pares de países capta, além dos termos de resistência multilateral, os custos de comércio bilaterais não observados diretamente, tais como os custos de transporte, particularidades geográficas e fatores históricos (CHENG e WALL, 2005).

Segunda, o presente trabalho utiliza dados de comércio desagregados por capítulos do Sistema Harmonizado (SH) para estimar o modelo gravitacional. Nesse caso, além das variáveis binárias para os pares de países, são adicionados efeitos fixos para os anos da amostra e para as 96 categorias de produtos (capítulos do $\mathrm{SH}$ ). A utilização de efeitos fixos por pares de países, associada à utilização de variáveis controles para a dimensão de produto e tempo, representa um aceitável compromisso entre a consistência teórica e o tratamento empírico (SHEPHERD e WILSON, 2008).

$\mathrm{O}$ terceiro aspecto refere-se à definição dos fluxos comerciais. Grande parte dos trabalhos empíricos utiliza como variável dependente as importações do país $i$ oriundas do país $j\left(M_{y j}^{k}\right)$. Isso se deve ao fato de que os dados de importação dos países tendem a ser melhor coletados que os dados de exportação (BALDWIN e TAGLIONI, 2006, p. 13).

A quarta consideração refere-se à definição da função que representa os custos de comércio que afetam as exportações do setor $k$ do país $j$ para o país $i\left(t_{i j}^{k}\right)$. No presente trabalho, esses custos são definidos como uma função de variáveis específicas das economias, de forma semelhante ao que fizeram Helble, 
Shepherd e Wilson (2007). Os custos de comércio são delineados de acordo com a equação a seguir:

$$
\ln \left(t_{i j}^{k}\right)=\beta_{3} \ln \left(1+\tau_{i}^{k}\right)+\beta_{4} \ln \left(b n t_{i}\right)+\sum_{m} \beta_{m} \ln \left(\operatorname{IFI}_{i}^{m}\right)+\sum_{n} \beta_{n} \ln \left(\operatorname{IFE}_{j}^{n}\right)
$$

em que $\tau_{i}^{k}$ é a tarifa média aplicada ao grupo de produtos $k$ pelo país importador $i$; $b n t_{i}$ é uma medida para a presença de barreiras não tarifárias na economia importadora $i$; $I F I_{i}^{m}$ são os $m$ Índices de Facilitação nas Importações do país $i$ construídos a partir da análise fatorial e $I F E_{j}^{n}$ representam os $n$ Índices de Facilitação nas exportações do país j, também construído com base na análise fatorial.

Dessa forma, considerando-se conjuntamente o modelo teórico apresentado na eq. (5), a estrutura da eq. (6) e a definição empírica dos fluxos de comércio bilateral, a especificação econométrica proposta para o presente estudo tem a seguinte forma:

$$
\begin{aligned}
& \ln \left(M_{i j}^{k}, t\right)=\alpha_{i j}+Y_{t}+\theta_{k}+\beta_{1} \ln \left(Y_{i, t}\right)+\beta_{2} \ln \left(Y_{j, t}\right)+\beta_{3} \ln \left(1+\tau_{i}^{k}\right)+ \\
& \beta_{4} \ln \left(b n t_{i}\right)+\sum_{m} \beta_{m} \ln \left(\operatorname{IFI} I_{i}^{m}\right)+\sum_{n} \beta_{n} \ln \left(I F E_{j}^{n}\right)+\varepsilon_{i j, t}^{k}
\end{aligned}
$$

em que $M_{i j, t}^{k}$ representa a importação realizada pelo país $i$ do país $j$ no setor $k$ no ano $t ; t=2003$ a 2006, $\alpha_{i j}$ são os efeitos fixos bilaterais invariantes no tempo; $Y_{t}$ representam as variáveis binárias para os anos da amostra; $\theta_{k}$ indicam as $k$ variáveis binárias para as categorias de produtos (Capítulos do $\mathrm{SH}$ ); $Y_{i, t}$ e $Y_{j, t}$ são o Produto Interno Bruto (PIB) do país importador $i$ e exportador $j$ no tempo $t$, respectivamente; e $\varepsilon_{i j, t}^{k}$ é o termo de erro aleatório. Para verificar a adequação e a robustez do modelo de efeitos fixos, estima-se também o modelo de efeitos aleatórios e o modelo pooled ${ }^{6}$.

Finalmente, cabe ressaltar que a equação (7) é uma logarítmica, uma equação gravitacional que assume que não existe comércio nulo. Entretanto, essa pressuposição é relativamente forte, particularmente quando se trabalha com bases de dados desagregadas por categorias de produtos. Assim, para se obter estimativas consistentes na presença de fluxos bilaterais que são zero na base de dados, o modelo gravitacional é estimado também pelo método Poisson Pseudo-Maximum-Likelihood(PPML) introduzido por Santos Silva e Tenreyro (2006). Esse método apresenta-se adequado, pois seus resultados são consistentes

6 Para expressar esse último modelo, são suprimidos da equação 7 os termos que expressam os efeitos fixos $\left(\alpha_{i j}+\gamma_{t}+\theta_{k}\right)$ e são incluídas mais três variáveis (dist $t_{i j}$ front $_{i j}$ e idioma $\left.a_{i j}\right)$, que tradicionalmente aparecem nos modelos gravitacionais que utilizam dados empilhados - dist ${ }_{i j}$ é a distância entre os dois países; front $t_{i j}$ é uma variável binária que assume valor 1 , caso os países compartilhem fronteiras comuns e valor 0 , caso não compartilhem; idioma $i j$ é representada por uma variável binária igual a 1, caso um par de países tenham um mesmo idioma, e 0 caso os idiomas sejam diferentes. 
na presença de heterocedasticidade e fornece estimativas robustas quando há valores zeros na variável dependente. Nesse caso, a eq. (7) é expressa na forma multiplicativa seguindo uma função exponencial com a variável depende expressa em nível, conforme demonstrado por Santos Silva e Tenreyro (2006) e por Siliverstovs e Schumacher (2007).

O modelo gravitacional é estimado para o período de 2003 a 2006 considerando-se dados do Brasil e de outros 42 países que figuram entre os principais parceiros comerciais do País7. Para determinar o tamanho da amostra utilizou-se como critério a disponibilidade de dados para a construção dos indicadores de facilitação de comércio, a importância do País para o comércio internacional mundial e para a balança comercial brasileira. Considerando-se a base de dados do presente estudo, o comércio entre esses países representou mais de $60 \%$ de todo o comércio internacional no período de 2003 a 2006. Além disso, os países considerados representaram, em $2006,80 \%$ do mercado de destino das exportações brasileiras e foram a origem de $70 \%$ das importações do País.

Os dados de importação, desagregados de acordo com o sistema harmonizado em dois dígitos (SH-2) no período de 2003 a 2006, são obtidos junto ao Comtrade. As estatísticas do Produto Interno Bruto (PIB) dos países no período de 2003 a 2006 foram obtidas junto ao Banco Mundial (World Development Indicators). A variável proxy para as Barreiras Não Tarifárias (BNT) de cada país é o equivalente ad valorem médio das BNTs calculadas por Kee, Nicita e Olarreaga $(2008)^{8}$. Já o MACMAP é a fonte para as informações desagregadas (SH-2) das tarifas aplicadas pelos países. Os dados da distância geográfica entre os países e das variáveis binárias para fronteiras compartilhadas e mesmo idioma são obtidos junto ao banco de dados do Centre D'Estudes Prospectives et d'Informations Internationales (CEPII, 2008).

7 Os países incluídos na regressão são Argentina (ARG), Austrália (AUS), Áustria (AUT), Bélgica (BEL), Brasil (BRA), Bulgária (BGR), Canadá (CAN), Chile (CHL), China (CHN), Chipre (CYP), República Checa (CZE), Dinamarca (DNK), Estônia (EST), Finlândia (FIN), França (FRA), Alemanha (DEU), Grécia (GRC), Hungria (HUN), Irlanda (IRL), Itália (ITA), Japão (JPN), Letônia (LVA), Lituânia (LTU), Luxemburgo (LUX), Malta (MLT), México (MEX), Países Baixos (NLD), Nova Zelândia (NLZ), Paraguai (PRY), Polônia (POL), Portugal (PRT), Romênia (ROM), Rússia (RUS), Arábia Saudita (SAU), Eslovênia (SVN), Eslováquia (SVK), África do Sul (ZAF), Espanha (ESP), Suécia (SWE), Inglaterra (GBR), Estados Unidos (USA), Coréia (KOR) e Uruguai (URY).

8 Kee, Nicita e Olarreaga (2008) estimaram o equivalente ad-valorem das barreiras não tarifárias (BNTs) de 78 países. Os autores consideram como componentes das BNTs medidas de controle de preços e de quantidade, medidas de monopólio e regulamentos técnicos. A partir dessas estimativas, os autores calculam três diferentes indicadores de restritividade, tanto das tarifas quando das barreiras não tarifárias. De acordo com os resultados dos autores, as BNTs contribuem com mais de $70 \%$ da média de proteção mundial. 


\section{Resultados}

\subsection{Resultados da Análise Fatorial}

Esta seção contém os resultados da análise fatorial utilizada visando reduzir o número de variáveis analisadas e, assim, sintetizar as variáveis associadas à facilitação de comércio em índices que avaliam as características dos países em termos de facilitação das importações e exportações.

\subsection{1. Índices de Facilitação nas Importações (IFIs)}

A análise fatorial parte da pressuposição da existência de correlação entre as variáveis. A Tabela 2 apresenta os coeficientes de correlação de Pearson entre as variáveis consideradas na análise. Verifica-se que todas as variáveis são positivamente correlacionadas e essas correlações são, em sua maioria, estatisticamente significativas?.

Os testes de esfericidade de Bartlett e de KMO foram utilizados para analisar a adequação dos dados à técnica. No que se refere ao teste de Bartlett, esse foi significativo a 1\%, rejeitando a hipótese nula de que a matriz de correlação é a matriz identidade. $\mathrm{O}$ teste de $\mathrm{KMO}$, por sua vez, apresentou valor de 0,83 .

Tabela 2. Matriz de correlação entre as variáveis incluídas na análise fatorial das medidas associadas à facilitação de comércio no âmbito das importações.

\begin{tabular}{|c|c|c|c|c|c|c|c|c|}
\hline & Favorit & $\begin{array}{c}\text { DP } \\
\text { Pagto } \\
\text { Irreg }\end{array}$ & $\begin{array}{c}\text { B } \\
\text { Camufl }\end{array}$ & TecInfor & $\begin{array}{c}\text { Clearance } \\
\text { Time }\end{array}$ & $\begin{array}{l}\text { Pagto } \\
\text { Irreg }\end{array}$ & $\begin{array}{l}\text { Doc } \\
\text { Exig } \\
\text { Imp }\end{array}$ & $\begin{array}{c}\text { Num } \\
\text { Agen } \\
\text { Imp }\end{array}$ \\
\hline Favorit & 1,00 & $0,87^{\mathrm{a}}$ & $0,77^{\mathrm{a}}$ & $0,73^{\mathrm{a}}$ & 0,32 & $0,81^{\mathrm{a}}$ & $0,49^{b}$ & 0,31 \\
\hline $\begin{array}{l}\text { DPPagto } \\
\text { Irreg }\end{array}$ & & 1,00 & $0,86^{\mathrm{a}}$ & $0,72^{\mathrm{a}}$ & $0,41^{\mathrm{c}}$ & $0,85^{\mathrm{a}}$ & $0,51^{\mathrm{a}}$ & $0,41^{\mathrm{c}}$ \\
\hline BCamufl & & & 1,00 & $0,60^{\mathrm{a}}$ & $0,41^{\mathrm{c}}$ & $0,80^{\mathrm{a}}$ & $0,41^{\mathrm{c}}$ & 0,36 \\
\hline TecInfor & & & & 1,00 & $0,54^{\mathrm{a}}$ & $0,68^{\mathrm{a}}$ & $0,59^{\mathrm{a}}$ & 0,32 \\
\hline $\begin{array}{l}\text { Tempo } \\
\text { Desemb }\end{array}$ & & & & & 1,00 & 0,40 & 0,33 & $0,56^{\mathrm{a}}$ \\
\hline PagtoIrreg & & & & & & 1,00 & 0,36 & 0,36 \\
\hline DocExigImp & & & & & & & 1,00 & $0,49^{b}$ \\
\hline $\begin{array}{l}\text { Num } \\
\text { AgenImp }\end{array}$ & & & & & & & & 1,00 \\
\hline
\end{tabular}

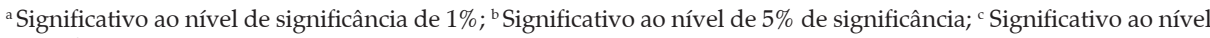
de $10 \%$ de significância.

Fonte: Resultados da pesquisa.

9 As correlações significativas a determinado nível de significância $(\alpha)$, devem ter probabilidade inferior a $[\alpha / n$. de correlações] (PESTANA e GAGEIRO, 2005). 
A Tabela 3 apresenta as cargas fatoriais, as comunalidades e a percentagem da variância total correspondente a cada fator após a rotação pelo método Varimax. As cargas fatoriais correspondem aos coeficientes de correlação entre cada fator e cada uma das oito variáveis. A comunalidade, por sua vez, é a parcela da variância de cada variável explicada pelos dois fatores identificados.

Ainda na Tabela 3 verifica-se que o fator $\left(\mathrm{F}_{1}\right)$, após a rotação, explica $49,14 \%$ da variabilidade total e está forte e positivamente correlacionado com as variáveis: Favorit, PagtoIrreg, DPPagtoIrreg, BCamufl e TecInfor. Mais especificamente, esse primeiro fator está fortemente associado com a importância e previsibilidade dos subornos pagos nos portos e com a presença de barreiras "camufladas". Essa associação permite interpretar esse fator como uma medida de facilitação de comércio no "ambiente" administrativo e político em que ocorrem as importações.

Tabela 3. Carga fatorial, comunalidades e percentagem da variância total correspondente ao fator identificado.

\begin{tabular}{lccc}
\hline & \multicolumn{2}{c}{ Carga Fatorial } & Comunalidade \\
\hline Favorit & $F 1$ & $F 2$ & \\
DPPagtoIrreg & 0,92 & 0,19 & 0,88 \\
BCamufl & 0,91 & 0,29 & 0,91 \\
TecInfor & 0,86 & 0,24 & 0,80 \\
TempoDesemb & 0,72 & 0,44 & 0,70 \\
PagtoIrreg & 0,22 & 0,79 & 0,67 \\
DocExigImp & 0,89 & 0,21 & 0,84 \\
NumAgenImp & 0,38 & 0,62 & 0,53 \\
Percentagem da variância & 0,13 & 0,86 & 0,76 \\
\hline
\end{tabular}

Fonte: Resultados da pesquisa.

O segundo fator $\left(\mathrm{F}_{2}\right)$ explica que $27,02 \%$ da variabilidade total dos dados está positivamente associado com as variáveis: NumAgenImp, TempoDesemb, DocExigImp. Essas variáveis são indicadores de facilitação de comércio no seu conceito mais estrito (elementos de fronteira) e, portanto, $\mathrm{o}_{2}$ pode ser interpretado como a facilitação do país nas importações vista sob a ótica da simplificação dos procedimentos de importação. Em outras palavras, esse segundo fator indica que melhorias na eficiência dos portos e menor burocracia para importar podem aumentar o grau de facilitação de comércio do país.

O resultado da análise fatorial permite agregar as variáveis correlacionadas com F1 em um índice agregado denominado "Índice de Facilitação nas 
Importações - ambiente administrativo e político" (IFI - "amb") $)^{10}$. O IFI "amb" é construído tomando-se a média simples das variáveis (padronizadas) correlacionadas com o F1. A Figura 1 apresenta IFI - "amb" para os países da amostra. No extremo mais baixo, menor grau de facilitação no ambiente administrativo, tem-se o Paraguai. O Brasil encontra-se entre os países com menor facilitação no ambiente administrativo e político associado às importações (primeiro quartil), com IFI - " $a m b$ " de 0,35; esse resultado reflete principalmente a presença de subornos e barreiras camufladas no País. Ainda no primeiro quartil do IFI - "amb" estão países como Romênia, Rússia, Argentina, China e México.

No último quartil estão as economias com maior grau de facilitação no "ambiente" administrativo e político em que ocorrem as importações. Dinamarca aparece no topo dessa classificação, refletindo a relativa ausência de pagamentos não oficiais e de favoritismo, bem como a adequada utilização da tecnologia da informação. Essas características também são responsáveis pelo bom desempenho de economias de países como Suécia, Nova Zelândia e Finlândia.

As variáveis NumAgenImp, TempoDesemb, DocExigImp estão correlacionadas com o Fator 2 e foram agregadas em um índice denominado "Índice de Facilitação nas Importações - simplificação dos procedimentos de importação" (IFI - "simp"). Esse índice contém informações sobre a facilitação de comércio vista sob a ótica de simplificação dos procedimentos de fronteira. $\mathrm{O}$ índice é construído tomando-se a média dessas três variáveis (padronizadas). Na escala do índice, 0 indica menor grau de facilitação e 1, maior grau de facilitação.

Figura 1. Índice de Facilitação nas Importações - ambiente administrativo e político (IFI - “amb") dos países selecionados.

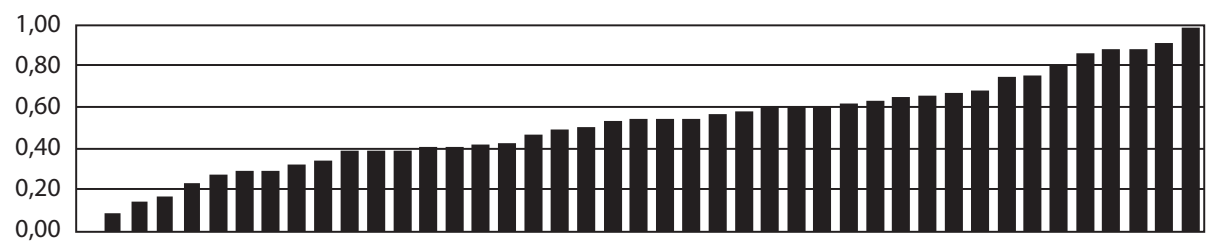

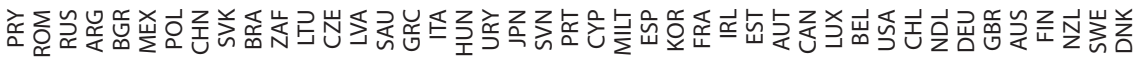

Fonte: Resultados da pesquisa.

10 Antes de construir índices a partir dos resultados da análise fatorial é necessária a verificação da consistência interna. O alpha de Cronbach é uma das medidas mais usadas na verificação da consistência interna. No presente trabalho, o F1 apresentou um alpha Cronbach de 0,94 e o F2 de 0,72. Esses resultados indicam, respectivamente, uma "muito boa" e "razoável" consistência interna (PESTANA e GAGEIRO, 2005). 
A Figura 2 contém o IFI - "simp" calculado para os países selecionados. O Paraguai aparece novamente no extremo mais baixo do índice, seguido de outros três países que apresentam IFI - "simp" relativamente abaixo dos demais países da amostra: Itália, Lituânia e Brasil. Enquanto que para o Paraguai e para a Itália o principal determinante dessa colocação na classificação geral é o elevado número de agências associadas à importação, para a Lituânia e para o Brasil, o problema está associado ao elevado tempo médio de desembaraço alfandegário, que é de 5,8 dias no Brasil.

Figura 2. Índice de Facilitação nas Importações - Simplificação dos procedimentos de importação (IFI - "simp") dos países selecionados.

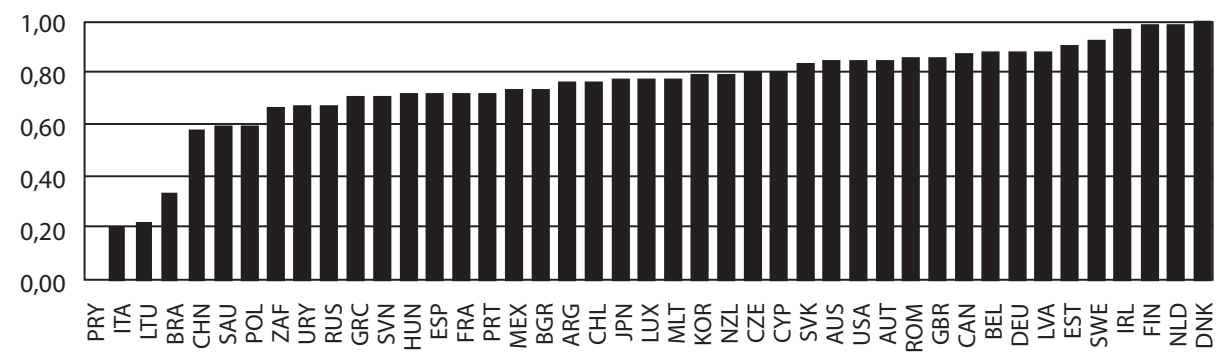

Fonte: Resultados da pesquisa.

De maneira geral, os países da amostra apresentaram IFI - "simp" relativamente elevados; a média do índice é de 0,74. Esse resultado indica que, nesses países, a burocracia para importar, bem como o tempo de desembaraço alfandegário são relativamente semelhantes. Dinamarca, Holanda, Finlândia e Irlanda figuram entre os países com melhor desempenho em termos de facilitação vista sob a ótica da simplificação dos procedimentos de importação.

\subsection{2. Índices de Facilitação nas Exportações (IFEs)}

Para sintetizar as variáveis associadas à facilitação de comércio que afetam as exportações do país, a análise fatorial é conduzida de maneira semelhante à apresentada na subseção anterior. A matriz de correlação entre as variáveis consideradas na análise fatorial conduzida para mensurar a facilitação nas exportações dos países é apresentada na Tabela $4^{11}$.

11 A construção dos Índices de Facilitação nas Importações (IFIs) considera um maior número de variáveis que as consideradas para construir os IFEs, isso porque alguns aspectos da facilitação, tais como a presença de barreiras "camufladas", são relevantes somente sob a ótica do importador. A variável NumAgenExp não é considerada na análise fatorial porque, diferente do esperado, não apresentou correlação 
Tabela 4. Matriz de correlação entre as variáveis incluídas na análise fatorial das medidas associadas à facilitação de comércio no âmbito das exportações.

\begin{tabular}{lccccc}
\hline & Favorit & $\begin{array}{c}\text { DPPagto } \\
\text { Irreg }\end{array}$ & $\begin{array}{c}\text { Tempo } \\
\text { Desemb }\end{array}$ & PagtoIrreg & DocExigExp \\
\hline Favorit & 1,00 & $0,87^{\mathrm{a}}$ & $0,32^{\mathrm{c}}$ & $0,81^{\mathrm{a}}$ & $0,51^{\mathrm{a}}$ \\
DPPagtoIrreg & & 1,00 & $0,41^{\mathrm{b}}$ & $0,85^{\mathrm{a}}$ & $0,48^{\mathrm{a}}$ \\
TempoDesemb & & & 1,00 & $0,40^{\mathrm{b}}$ & 0,27 \\
PagtoIrreg & & & 1,00 & $0,42^{\mathrm{b}}$ \\
DocExigExp & & & & 1,00 \\
\hline
\end{tabular}

${ }^{a}$ Significativo ao nível de significância de $1 \%$; ${ }^{\mathrm{b}}$ Significativo ao nível de $5 \%$ de significância; ${ }^{\text {c Significativo ao nível }}$ de $10 \%$ de significância.

Fonte: Resultados da pesquisa.

Os resultados dos testes de esfericidade de Bartlett (significativo a 1\%) e de $\mathrm{KMO}(0,81)$ permitem concluir que a técnica de análise fatorial pode ser aplicada nesse conjunto de dados. O resultado da análise de componentes principais identificou apenas um autovalor superior à unidade. $O$ fator associado a esse autovalor explica $64,81 \%$ da variância total das variáveis incluídas. Esse resultado indica que as cinco variáveis que avaliam a facilitação de comércio podem ser explicadas por apenas um fator, que pode ser interpretado como o grau de facilitação de comércio dos países nas exportações.

A Tabela 5 apresenta as cargas fatoriais, as comunalidades e a percentagem da variância total do fator. De forma semelhante ao fator relacionado à facilitação nas importações, as variáveis que mensuram a presença de suborno e favoritismo estão significativamente correlacionadas com o fator que identifica a facilitação nas exportações do país. Adicionalmente, a correlação existente entre o fator e as variáveis DocExigExp e TempoDesemb indicam que a excessiva burocracia para exportar, bem como um desembaraço alfandegário demorado, ceterisparibus, reduzem o grau de facilitação nas exportações dos países.

estatisticamente significativa ao nível de 10\% com nenhuma das demais variáveis incluídas na análise. 
Tabela 5. Carga fatorial, comunalidades e percentagem da variância total correspondente ao fator identificado.

\begin{tabular}{lcc}
\hline & Carga Fatorial & Comunalidade \\
\cline { 2 - 3 } & $F 1$ & \\
\hline Favorit & 0,92 & 0,84 \\
DPPagtoIrreg & 0,94 & 0,88 \\
TempoDesemb & 0,54 & 0,29 \\
PagtoIrreg & 0,91 & 0,82 \\
DocExigExp & 0,64 & 0,41 \\
\hline
\end{tabular}

Fonte: Resultados da pesquisa.

Os resultados da análise fatorial foram utilizados para construir um índice agregado denominado "Índice de Facilitação nas Exportações - IFE"12. O IFE é construído tomando-se a média das cinco variáveis, e então é criada uma escala para o índice, que varia entre 0 e 1 , sendo que 0 está associado à baixa facilitação e 1, à elevada facilitação relativa nas exportações. A Figura 3 apresenta o IFE construído para os países que compõem a amostra deste trabalho.

Figura 3. Índice de Facilitação nas Exportações (IFE) dos países selecionados.

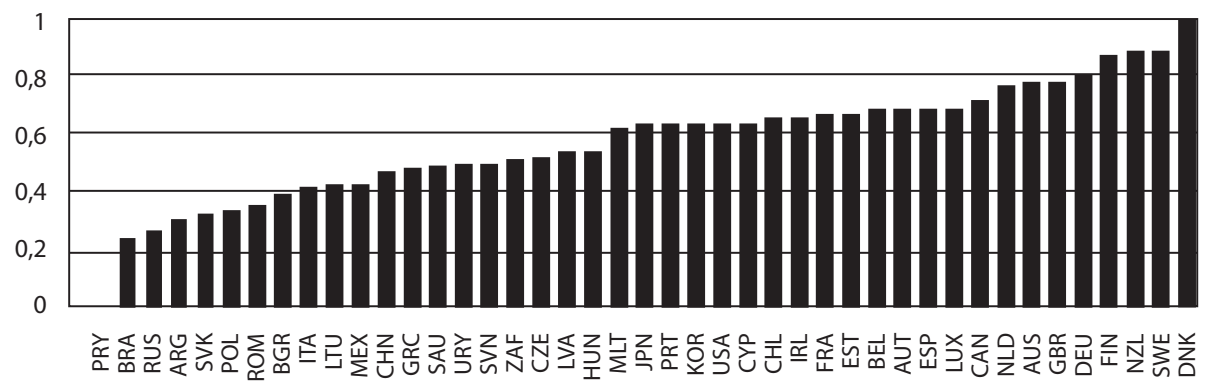

Fonte: Resultados da pesquisa.

De forma semelhante aos índices relacionados à facilitação nas importações, Paraguai e Dinamarca aparecem nos dois extremos do IFE, sendo que a presença e a previsibilidade do nível de pagamentos não oficiais são os determinantes dessa posição na classificação. No caso do Brasil, o baixo índice de facilitação nas exportações é explicado pelo desembaraço alfandegário, que é relativamente elevado no Brasil e, portanto, recebe maior peso no IFE do país. A presença

12 O alpha de Cronbach, utilizado para verificar a consistência interna do F1, apresentou valor de 0,85 . Esse resultado permite classificar a consistência interna como "boa". 
de suborno associado aos procedimentos de exportação também contribui para essa posição do Brasil na classificação. A média do IFE é de 0,57, e 20 países apresentam facilitação nas exportações menor que o valor médio ${ }^{13}$.

\subsection{Impactos da facilitação no padrão de comércio internacional: resultados do modelo gravitacional}

Esta seção contém os resultados das estimativas da equação gravitacional empregada para mensurar os impactos dos índices de facilitação de comércio sobre o padrão dos fluxos de comércio bilateral.

\subsubsection{Procedimento de estimação}

A Tabela 6 apresenta, respectivamente, os resultados das estimativas obtidas pelo modelo de regressão Pooled, Efeitos Fixos (MQO e PPML) e Efeitos Aleatórios. Verifica-se, a partir do teste $\mathrm{F}$ (Chow), que é aplicado ao modelo de efeitos fixos, e do teste do Multiplicador de Lagrange de Breusch e Pagan (1980), aplicado ao modelo de efeitos aleatórios, que não é possível rejeitar a hipótese de que efeitos de heterogeneidades não observáveis dos países afetam o comércio bilateral. O teste de Hausmann mostra que a hipótese nula de ausência de correlação entre os efeitos não observáveis do país e as variáveis exógenas do modelo devem ser rejeitadas, indicando que o modelo de efeitos fixos deve apresentar estimativas consistentes, apresentando-se, portanto, como o modelo mais eficiente.

Deve ser destacado, ainda, que os resultados do modelo de efeito fixo estimado pelo método (PPML) são relativamente melhores em termos dos sinais esperados pela teoria, assim como em termos da magnitude dos coeficientes estimados. Os coeficientes associados à renda dos países estimados pelo modelo EF-PPML são mais próximos à unidade como previsto no modelo teórico da equação gravitacional (ANDERSON e WINCOOP, 2003, p. 14; SANTOS SILVA e TENREYRO, 2006, p. 643). No que se refere aos índices de facilitação, diferente do modelo de EF - MQO, o sinal do IFI - "amb" é positivo de acordo com o esperado. Isso indica que melhorias em termos de facilitação no ambiente administrativo e político em que ocorre a importação ampliariam

13 Como mencionado, a utilização dessa técnica da analise fatorial facilita a análise econométrica, pois reduz os problemas causados pela correlação esperada entre algumas das variáveis. De fato, não se observou correlação estatisticamente significativa entre os IFI - "simp" e IFI - "amb" construídos através da análise fatorial. Adicionalmente, como cada linha da base de dados do modelo gravitacional incluí indicadores de facilitação de dois países distintos, o exportador e o importador, não se observa correção dos IFI com o IFE. 
o comércio bilateral entre os países. Como a base de dados do presente trabalho é desagregada em capítulos do $\mathrm{SH}$, possui um número elevado de observações de comércio bilateral nulo; neste caso, é preferível a utilização de um modelo que apresenta resultados robustos na presença desse viés de seleção (SANTOS SILVA e TENREYRO, 2006; SHEPHERD e WILSON, 2008; WESTERLUND e WILHELMSSON, 2006; SILIVERSTOVS e SCHUMACHER, 2007).

Tabela 6. Resultados das Estimativas da Equação Gravitacional.

\begin{tabular}{|c|c|c|c|c|}
\hline & \multicolumn{4}{|c|}{ Modelo } \\
\hline & \multirow{2}{*}{$\begin{array}{c}\text { Regressão } \\
\text { Pooled }\end{array}$} & $\begin{array}{l}\text { Efeitos } \\
\text { Fixos }\end{array}$ & $\begin{array}{l}\text { Efeitos } \\
\text { Fixos }\end{array}$ & \multirow{2}{*}{$\begin{array}{l}\text { Efeitos Aleatórios } \\
\text { (EA) }\end{array}$} \\
\hline & & $(E F-M Q O)$ & $\begin{array}{c}(E F- \\
P P M L)\end{array}$ & \\
\hline \multirow[t]{2}{*}{ 1Pib_imp } & $0,755^{*}$ & $0,125^{*}$ & $0,651^{*}$ & $0,719^{*}$ \\
\hline & $(0,003)$ & $(0,047)$ & $(0,043)$ & $(0,010)$ \\
\hline \multirow[t]{2}{*}{ 1Pib_exp } & $0,855^{*}$ & $0,288^{*}$ & $0,616^{*}$ & $0,879^{*}$ \\
\hline & $(0,003)$ & $(0,048)$ & $(0,042)$ & $(0,010)$ \\
\hline \multirow[t]{2}{*}{ Ltarif } & $-1,601^{*}$ & $-2,079^{*}$ & $-1,982^{*}$ & $-2,233^{*}$ \\
\hline & $(0,071)$ & $(0,383)$ & $(0,619)$ & $(0,097)$ \\
\hline \multirow[t]{2}{*}{ Lbnt } & $-0,121^{*}$ & $-0,110^{*}$ & $-0,0278$ & $-0,116^{*}$ \\
\hline & $(0,007)$ & $(0,039)$ & $(0,067)$ & $(0,008)$ \\
\hline \multirow[t]{2}{*}{ Ldist } & $-0,969^{*}$ & - & - & - \\
\hline & $(0,004)$ & - & - & - \\
\hline \multirow[t]{2}{*}{ Front } & $0,871^{*}$ & - & - & - \\
\hline & $(0,019)$ & - & - & - \\
\hline \multirow[t]{2}{*}{ Idioma } & $0,565^{*}$ & - & - & - \\
\hline & $(0,017)$ & - & - & - \\
\hline \multirow[t]{2}{*}{ IIFI - “amb" } & $0,080^{*}$ & $-0,233^{*}$ & $0,669^{* *}$ & $-0,134^{*}$ \\
\hline & $(0,010)$ & $(0,115)$ & $(0,294)$ & $(0,020)$ \\
\hline \multirow[t]{2}{*}{ IIFI - "simp" } & $-0,116^{*}$ & $0,303^{*}$ & 0,134 & $0,334^{*}$ \\
\hline & $(0,013)$ & $(0,105)$ & $(0,145)$ & $(0,017)$ \\
\hline \multirow[t]{2}{*}{ IIFE } & $0,126^{*}$ & 0,047 & $0,765^{* *}$ & $0,217^{*}$ \\
\hline & $(0,014)$ & $(0,199)$ & $(0,421)$ & $(0,033)$ \\
\hline \multirow[t]{2}{*}{ Constante } & $-21,871^{*}$ & $-1,794$ & - & $-33,53^{*}$ \\
\hline & $(0,110)$ & $(2,507)$ & - & 0,514 \\
\hline $\mathrm{R} 2$ & 0,305 & 0,352 & - & 0,351 \\
\hline
\end{tabular}




\begin{tabular}{|c|c|c|c|c|}
\hline & \multicolumn{4}{|c|}{ Modelo } \\
\hline & \multirow{3}{*}{$\begin{array}{c}\text { Regressão } \\
\text { Pooled }\end{array}$} & Efeitos & Efeitos & \multirow{3}{*}{$\begin{array}{c}\text { Efeitos Aleatórios } \\
\text { (EA) }\end{array}$} \\
\hline & & Fixos & Fixos & \\
\hline & & $\begin{array}{c}(E F- \\
M Q O)\end{array}$ & $\begin{array}{c}(E F- \\
P P M L)\end{array}$ & \\
\hline Observações & 433250 & 433250 & 614592 & 433250 \\
\hline Grupos (pares de países) & - & 860 & 860 & 860 \\
\hline Teste F (Chow) & - & $248^{*}$ & - & - \\
\hline Teste Breusch e Pagan & - & - & - & $13000000^{*}$ \\
\hline Teste de Hausman & - & - & - & $1158^{*}$ \\
\hline \multicolumn{5}{|l|}{ Variáveis de Controle } \\
\hline Binárias - anos 03-06 & Não & Sim & Sim & Sim \\
\hline Binárias - categ. de produtos (96) & Não & Sim & Sim & Sim \\
\hline
\end{tabular}

* : denota significância a $1 \%$.

** : denota significância a $5 \%$.

Para os modelos de Efeito Fixo e Efeito Aleatório é reportado o $\mathrm{R}^{2}$ "withingroups".

Valores entre parênteses indicam o erro padrão robusto (robust standard error).

Fonte: Resultados da pesquisa.

\subsubsection{Resultados da estimativa do modelo de efeito fixo}

A Tabela 7 apresenta os resultados das estimativas da equação gravitacional por efeito fixo (EF - PPML) para diferentes agregações dos Capítulos do Sistema Harmonizado $(\mathrm{SH})$. A primeira coluna, equivalente à terceira coluna da Tabela 6, abrange todos os capítulos do Sistema Harmonizado. A segunda coluna exclui matérias-primas (Capítulos 1-27) e a terceira coluna exclui manufaturas básicas (Capítulos 1-83). Verifica-se que, de maneira geral, os coeficientes estimados apresentaram os sinais esperados e são estatisticamente significativos.

Os coeficientes de Produto Interno Bruto dos países exportadores e importadores apresentam-se positivo e estatisticamente significativo ao nível de $1 \%$ nas três agregações estimadas. Os resultados corroboram com os de Santos Silva e Tenreyro (2006), Helble, Shepherd e Wilson (2007), Liu (2007) e Siliverstovs e Schumacher (2007). O coeficiente pode ser interpretado como uma elasticidade do comércio bilateral ao tamanho econômico dos países da amostra. $\mathrm{O}$ coeficiente para a tarifa aplicada se apresenta negativo, conforme esperado, e estatisticamente significativo. Esses resultados corroboram com os resultados encontrados por Helble, Shepherd e Wilson (2007). Ao utilizar dados para Apec, esses autores estimaram que uma redução das tarifas aplicadas em 
$1 \%$ está associada com um aumento de 2,8\% no comércio bilateral entre os países membros.

No que se refere ao impacto do equivalente ad valorem (AVE) das barreiras não tarifárias (BNTs), o coeficiente estimado não foi significativo estatisticamente para as três amostras. Helble, Shepherd e Wilson (2007) e Disdier, Fontagné e Mimouni (2007) encontraram coeficientes estatisticamente significativos para o AVE das BNTs. No entanto, diferente das estimativas conduzidas por esses autores, o presente trabalho não dispõe de informações desagregadas por capítulos do $\mathrm{SH}$ do equivalente ad valorem das barreiras não tarifárias. Assim, a baixa magnitude e significância dos coeficientes estimados podem estar refletindo essa limitação.

Os resultados para as três variáveis que representam o foco principal deste trabalho - os índices de facilitação nas importações e o índice de facilitação nas exportações - indicam uma relação positiva e estatisticamente significativa com o comércio. Esse resultado sugere que melhorias nas áreas de facilitação de comércio que levariam a um incremento relativo dos índices poderiam estimular os fluxos de comércio entre os países.

De maneira semelhante ao identificado por Helble, Shepherd e Wilson (2007), os impactos da facilitação parecem ser mais expressivos para produtos com maior grau de processamento do que para matérias-primas. Produtos com maior grau de processamento estão mais sujeitos a problemas associados aos procedimentos de fronteira, como por exemplo, classificação errada das mercadorias na aduana. Por outro lado, matérias-primas e produtos agrícolas são mais homogêneos, o que os torna menos sujeitos a esse tipo de problema ${ }^{14}$.

Primeiramente, os resultados do IFI - "amb", índice que avalia a facilitação de comércio, considerando-se o "ambiente" político e administrativo em que ocorrem as importações, sugerem que a redução das barreiras camufladas, dos níveis de suborno e favoritismo no país importador, pode proporcionar ganhos para o comércio. Esses resultados corroboram com os de Wilson, Mann e Otsuki (2005). Ao utilizar um índice para o "ambiente" alfandegário, composto pelas medidas de barreiras "camufladas" e pagamentos irregulares, os autores encontraram que melhorias nessas áreas impactam positivamente o comércio. Concluem que a facilitação de comércio por meio de melhorias nas alfândegas é um caminho possível para reduzir os custos de importação. Shepherd e Wilson (2008) também reforçam que o comércio de produtos industrializados entre os membros da Asean (Associação de Nações do Sudeste Asiático) são sensíveis à presença de pagamentos irregulares associados com as importações e exportações.

14 Os resultados de Helble, Shepherd e Wilson (2007) mostram que as medidas de facilitação são relativamente mais importantes para produtos heterogêneos. 
O segundo índice, que mede a facilitação de comércio dos países sob a ótica da simplificação dos procedimentos de fronteira (IFI - "simp"), também se apresenta positivamente associado com o comércio bilateral, sendo estatisticamente significativo nos modelos que excluem matérias-primas (segunda e terceira coluna). Considerando-se as estimativas da segunda e da terceira coluna, os resultados corroboram com os efeitos sinalizados pela literatura, tais como os de Apec (1999), Hertel, Walmsley e Itakura (2001), Unctad (2001), Fox, Françoise Landoño-Kent (2003), OECD (2003) e Francois, Meijl e Tongerem (2005).

Considerando-se as estimativas da segunda e terceira colunas, nota-se que a facilitação via simplificação dos procedimentos de importação teve um impacto relativamente menor sobre o comércio do que o IFI - "amb". De um lado, isso reflete o resultado visualizado na Figura 2, que mostra que os países, de maneira geral, possuem um nível relativamente elevado e semelhante de simplificação. Por outro lado, a comparação entre esses dois índices pode sugerir uma prioridade de política dos países importadores no que se refere à facilitação de comércio. Ou seja, os resultados da Figura 1 associados às estimativas do modelo gravitacional sugerem que avanços nas áreas que compõem o IFI "amb" são necessários. Além disso, os possíveis impactos dessas melhorias no comércio dos países envolvidos seriam positivos. 
Tabela 7. Resultados das estimativas da Equação Gravitacional pelo modelo de Efeitos Fixos (EF - PPML) para diferentes agregações dos Capítulos do SH.

\begin{tabular}{|c|c|c|c|}
\hline & \multirow{2}{*}{$\begin{array}{l}\text { Todos os } \\
\text { produtos }\end{array}$} & \multicolumn{2}{|c|}{$\begin{array}{c}\text { Modelo Efeitos Fixos } \\
\text { (EF - PPML) }\end{array}$} \\
\hline & & $S H>27$ & $S H>83$ \\
\hline \multirow{2}{*}{ 1Pib_imp } & $0,65^{*}$ & $0,64^{*}$ & $0,75^{*}$ \\
\hline & $(0,04)$ & $(0,04)$ & $(0,08)$ \\
\hline \multirow{2}{*}{ lPib_exp } & $0,62^{*}$ & $0,63^{*}$ & $0,85^{*}$ \\
\hline & $(0,04)$ & $(0,05)$ & $(0,08)$ \\
\hline \multirow{2}{*}{ Ltarif } & $-1,98^{*}$ & $-3,27^{*}$ & $-3,13^{*}$ \\
\hline & $(0,62)$ & $(1,02)$ & $(1,10)$ \\
\hline \multirow{2}{*}{ Lbnt } & $-0,03$ & $-0,03$ & $-0,03$ \\
\hline & $(0,07)$ & $(0,07)$ & $(0,09)$ \\
\hline \multirow{2}{*}{ IIFI - "amb" } & $0,67^{* *}$ & $0,96^{*}$ & $1,50^{*}$ \\
\hline & $(0,29)$ & $(0,30)$ & $(0,44)$ \\
\hline \multirow{2}{*}{ IIFI - “simp” } & 0,13 & $0,25^{* *}$ & $0,46^{* *}$ \\
\hline & $(0,14)$ & $(0,15)$ & $(0,20)$ \\
\hline \multirow{2}{*}{ IIFE } & $0,77^{* *}$ & $1,35^{*}$ & $2,40^{*}$ \\
\hline & $(0,42)$ & $(0,45)$ & $(0,68)$ \\
\hline Observações & 614592 & 448140 & 96030 \\
\hline Grupos (pares de países - 860) & Sim & Sim & Sim \\
\hline Binárias - anos 03-06 & Sim & Sim & Sim \\
\hline Binárias - categ. de produtos & Sim & Sim & Sim \\
\hline
\end{tabular}

Erro padrão robusto entre parênteses.

*: denota significância a $1 \%$.

**: denota significância a $5 \%$.

Fonte: Resultados da pesquisa.

Por fim, porém não menos importante, está o índice que mede a facilitação dos países nas exportações (IFE). De maneira semelhante ao que ocorre com os IFIs, quanto maior o grau de processamento dos produtos, maior a importância das medidas de facilitação na determinação do comércio. Os resultados da Tabela 7 parecem sugerir que importantes ganhos podem ser obtidos por meio da facilitação de comércio unilateral, visto que aumentos no grau de facilitação nos países exportadores têm um positivo e significativo impacto sobre o padrão de comércio bilateral. Esses resultados confirmam os de Wilson, Mann e Otsuki 
(2005), que indicam que mais de $50 \%$ dos ganhos com a facilitação de comércio viriam de melhorias nos países exportadores.

De maneira geral, os resultados apresentados na Tabela 7 indicam que o grau de facilitação dos países, seja como importador ou exportador, é um importante determinante do padrão de comércio entre eles. Embora as barreiras tarifárias apareçam como um limitante expressivo, os resultados indicam que os países podem ampliar o comércio bilateral por caminhos alternativos, como reformas que promovam a facilitação comercial e reduzam os custos de comercialização internacional.

\section{Conclusão}

A construção de indicadores de facilitação, por meio da técnica da análise fatorial associada a estimativas econométricas da equação gravitacional mostrou-se adequada para avaliar como as diversas medidas de facilitação comercial afetam o padrão de comércio dos países. De maneira geral, a relação positiva e significativa encontrada entre os índices e os fluxos de comércio bilateral indica que os países podem ampliar seu intercâmbio comercial por meio de reformas que promovam a facilitação de comércio e reduzam os custos de comercialização internacional.

Os resultados na análise fatorial sugerem algumas prioridades para os países no sentido de reformas que promovam um comércio mais facilitado: a redução das barreiras não tarifárias, do favoritismo nas decisões administrativas e dos níveis de pagamentos não oficiais. Essas variáveis são altamente correlacionadas com os índices de facilitação e têm relativa importância para a maioria dos países considerados. Essa prioridade pode ser inferida também do resultado das análises econométricas, que sugerem que avanços nas áreas que compõem o IFI - "amb", índice que avalia a facilitação nas importações considerando-se o "ambiente" político e administrativo, têm impacto relativamente maior no comércio do que melhorias advindas da simplificação dos procedimentos de importação. Desse resultado, deriva-se que a consolidação de um ambiente institucional e regulatório que promova a facilitação, reduzindo os efeitos negativos de medidas que impactam o comércio de maneira "camuflada" são elementos essenciais para avanços significativos na direção da facilitação de comércio nesses países.

Outro resultado do modelo gravitacional que deve ser destacado é que melhorias em termos de facilitação nos países exportadores têm um positivo e significativo impacto sobre o padrão de comércio bilateral relativo a melhorias nos países importadores. Esse resultado é interessante sob o ponto de vista dos países exportadores, pois indica que o país pode ampliar significativamente seu comércio por meio de reformas unilaterais realizadas internamente. 
Os resultados evidenciam que os impactos da facilitação são mais expressivos para produtos com maior grau de processamento do que para matérias-primas, indicando que os benefícios da facilitação podem depender do tipo de produto em questão, ou, ainda, do perfil da pauta de importação e exportação dos países.

O trabalho indica que avanços na direção da facilitação de comércio são particularmente importantes para o Brasil. O País tem o tempo de desembaraço alfandegário maior relativamente aos demais países, além de problemas associados à presença de barreiras camufladas e subornos na economia. Nesse sentido, a direção de esforços para essas áreas poderia trazer mais eficiência e custos menores para os exportadores e importadores nacionais. Adicionalmente, as evidências empíricas sugerem que os ganhos são potencializados quando o maior número de países realiza reformas. Nesse sentido, os resultados sugerem para o Brasil uma postura ativa no direcionamento de negociações sobre facilitação de comércio na OMC.

Cabe ressaltar que este trabalho sinaliza alguns dos possíveis impactos da facilitação de comércio. Além dos impactos sobre o comércio bilateral, avanços em termos de facilitação podem criar ambiente favorável a investimentos estrangeiros, ampliar a integração econômica e trazer impactos sobre o bem-estar. Esses assuntos merecem atenção em trabalhos futuros com relação à facilitação de comércio.

\section{Referências bibliográficas}

ALMEIDA, F. M.; SILVA; O. M.; LIMA, J. E. Determinantes das notificações aos acordos sobre medidas SPS e TBT emitidas pelo Brasil. In: SILVA, O.M. Notificações aos Acordos de Barreiras Técnicas (TBT) e Sanitárias(SPS) da OMC: transparência comercial ou barreiras não tarifárias? Viçosa: Suprema, 2010.Cap. 8, p. 155-180.

ANDERSON, J.; WINCOOP, E. Gravity with gravitas: a solution to the border puzzle. American Economic Review, Nashville, v. 93, n. 1, p. 170-192, 2003. Disponível em: <http://ideas.repec.org/a/aea/aecrev/v93y2003i1p170-192. html\#provider >. Acesso em: 10 mai. 2010.

. Trade costs. Boston, 2004.101 p. (Boston College Working Papers in Economics, 593). Disponível em: <http://ideas.repec.org/p/boc/bocoec/593. html >. Acesso em: 10 mai. 2010.

ASIA PACIFIC ECONOMIC COOPERATION - APEC. Assessing APEC trade liberalization and facilitation: 1999 update. Cingapura: APEC Economic Committee, 1999.55 p. Disponível em: < http://www.apec.org/apec/publications/ all_publications/economic_committee.html\#2004>. Acesso em: 5 mai. 2008. 
.Tradefacilitation and trade liberalization: from Shanghai to Bogor. Cingapura: APEC Economic Committee, 2004. 95 p. Disponível em: < http://www.apec.org/ apec/publications/all_publications/economic_committee.html\#2004>. Acesso em: 5 maio 2009.

BALDWIN, R.E.; TAGLIONI, D. Gravity for dummies and dummies for gravity equations. London, 2006. (CEPR Discussion Paper, 5850). Disponível em: <http:// ssrn.com/abstract $=945443>$. Acesso em: 12 maio 2009.

BANCO MUNDIAL. World development indicators online. Disponível em: < http:// web.worldbank.org/WBSITE/EXTERNAL/DATASTATISTICS/0,,contentMDK:2 0398986 isCURL:Y pagePK:64133150 piPK:64133175 theSitePK:239419,00. html>. Acesso em: 13 jun. 2009.

CENTRE D'ESTUDES PROSPECTIVES ET D'INFORMATIONS INTERNATIONALES - CEPII. News. Disponível em: < http://www.cepii.fr/ anglaisgraph/news/accueilengl.htm > . Acesso em: 28 nov. 2009.

CHENG, I.; WALL, H.J. Controlling for heterogeneity in gravity models of trade and integration. Federal Reserve Bank of St. Louis Review, St. Louis, v. 87, n. 1, p. 49-63, 2005. Disponível em: <http://ssrn.com/abstract=656201>. Acesso em: 28 nov. 2009.

COMMODITY TRADE STATISTICS-COMTRADE. United Nations commodity trade statistics database. Disponível em: <http://comtrade.un.org/db > . Acesso em: 13 jun. 2009.

DISDIER, A.; FONTAGNÉ, L.; MIMOUNI, M. The impact of regulations on agricultural trade: evidence from the SPS and TBT agreements. American Journal of Agricultural Economics, Oxford, v. 90, n. 2, p. 336-350, 2008. Disponível em: $<$ http://ssrn.com/abstract $=1119018$ > . Acesso em: 17 abr. 2010.

DJANKOV, S.; FREUND, C.; PHAM, C.S. Trading on time. Washington, 2006.39 p. (World Bank Policy Research Working Paper, 3909). Disponível em: < http:// ideas.repec.org/p/wbk/wbrwps/3909.html>. Acesso em: 25 abr. 2008.

DOING BUSINESS. Doing business in 2007: how to teform.Washington: World Bank, 2007. 185 p. Disponível em: <http://www.doingbusiness.org>. Acesso em: 13 jun. 2008.

DUVAL, Y. Cost and benefits of implementing trade facilitation measures under negotiations at the WTO: an exploratory survey. Bangkok: Asia-Pacific Research and Training Network on Trade - ARTNeT, 2006. 40 p. (Working Papers, 306). Disponível em: $<$ http://ideas.repec.org/p/esc/wpaper/306.html>. Acesso em: 23 jan. 2009.

FARIA, R.N.; BURNQUIST, H.L. Análise do grau de restritividade de exigências técnicas às exportações brasileiras. Revista de Economia e Agronegócio, Viçosa, v. 4, no 4, p. 411-430, out./dez. 2006. 
FEENSTRA, R.C. Advanced international trade: theory and evidence. Princeton: Princeton University Press, 2004. 484 p.

FOX, A.K.; FRANÇOIS, J.F; LONDONO-KENT, P. Measuring border crossing costs and their impact on trade flows: The United States-Mexican trucking case. West Lafayette, 2003. 17 p. (GTAP Resource, 1282). Disponível em: <https://www. gtap.agecon.purdue.edu/resources/res_display.asp?RecordID $=1282>$. Acesso em: 22 abr. 2008.

FRANÇOIS, J.F; MEIJL, H. van; TONGEREN, F. van.Trade liberalization in the Doha development round.Economic Policy, London, v. 20, n. 42, 2005. Disponível em: <http://ideas.repec.org/a/bla/ecpoli/v20y2005i42p349-391.html>. Acesso em: 22 abr. 2008.

FRATIANNI, M. The gravity equation in international trade. Bloomington: Indiana University, Kelley School of Business, 2007. 30 p. (Working Papers, 2007-17). Disponível em: <http://ideas.repec.org/p/iuk/wpaper/2007-17.html>. Acesso em: 5 jun. 2008.

GLOBAL COMPETITIVENESS REPORT. The global competitiveness report 20042005. Disponível em: <http://www.weforum.org/en/initiatives/gcp/Global\%20 Competitiveness\%20Report/PastReports/index.htm > . Acesso em: 13 jun. 2008.

GLOBAL TRADE NEGOTIATIONS - GTN. Trade facilitation summary.Disponível em: < http://www.cid.harvard.edu/cidtrade/issues/tradefac.html > . Acesso em: 27 jan. 2008.

HELBLE, M.; SHEPHERD, B.; WILSON, J.S. Transparency and trade facilitation in the Asia Pacific: estimating the gains from reform. Washington: World Bank Development Research Group, 2007. 84 p. Disponível em: <http:// siteresources.worldbank.org/INTTRADECOSTANDFACILITATION/Resources/ Transparency-APEC-Study-Fin.pdf>. Acesso em: 23 jan. 2008.

HERTEL, T.W.; WALMSLEY, T.; ITAKURA, K. Dynamic effects of the "new age" free trade agreement between Japan and Singapore.West Lafayette, 2001.45 p. (GTAP Working Paper, 823). Disponível em: < http://ideas.repec.org/p/gta/workpp/823. html>. Acesso em: 20 abr. 2008.

HUMMELS, D. Time as a trade barrier.West Lafayette, 2001.35 p. (GTAP Working Papers, 1152). Disponível em: <http://ideas.repec.org/p/gta/workpp/1152. html>. Acesso em: 20 abr. 2008.

INSTITUTO DE ESTUDOS DO COMÉRCIO E NEGOCIAÇÕES INTERNACIONAIS - ICONE. Negociações em facilitação de comércio. Disponível em: <http://www.iconebrasil.org.br/pt/default.asp?actA=15\&areaID =14\&seca oID=28\&faq_assuntoID=14 > . Acesso em: 14 fev. 2008 . 
JOHNSON, R.A.; WICHERN, D.W. Applied multivariate statistical analysis.4.ed. New Jersey: Prentice Hall, 1998. 816 p.

KEE, H.L.; NICITA, A.; OLARREAGA, M. Estimating trade restrictiveness indices. Washington, 2008.36 p. (World Bank Policy Research Working Paper, 3840). Disponível em: < http://ideas.repec.org/p/wbk/wbrwps/3840.html>. Acesso em: 15 mai. 2008.

LIU, X. GATT/WTO promotes trade strongly: sample selection and model specification. In:ANNUAL CONFERENCE ON GLOBAL ECONOMIC ANALYSIS, 10., West Lafayette, 2007. Anais. West Lafayette: Purdue University, 2007. Disponível em: <https://www.gtap.agecon.purdue.edu/resources/res display.asp?RecordID=2316>. Acesso em: 28 nov. 2008.

LOGISTICS PERFORMANCE INDEX. Connecting to compete: trade logistics in the global economy, the logistics performance index and its indicators. Washington: World Bank, 2007. Disponível em:<http://web.worldbank.org/ WBSITE/EXTERNAL/TOPICS/EXTTRANSPORT/EXTTLF/0,,contentMDK:2151 4122 menuPK:3875957 pagePK:210058 piPK:210062 theSitePK:515434,00. html>. Acesso em: 13 jun. 2008.

MARKET ACCESS MAP - MACMAP. UNCTAD/WTO. Disponível em: < http:// www.macmap.org >. Acesso em: 13 jun. 2008.

NAÇÕES UNIDAS. Global e-government readiness reports.Disponível em: < http:// www2.unpan.org/egovkb/global_reports/index.htm > . Acesso em: 13 jun. 2008.

ORGANISATION FOR ECONOMIC CO-OPERATION AND DEVELOPMENT - OECD. Quantitative assessment of the benefits of trade facilitation. Paris, 2003. 29 p. (OECD Trade Policy Working Papers TD/TD/WP(2003)31/FINAL). Disponível em: < http://ideas.repec.org/p/wpa/wuwpit/0401008.html>. Acesso em: 20 abr. 2008.

.The economic impact of trade facilitation. Paris, 2005. 31 p. (OECD Trade Policy Working Papers Working Paper TD/TC/WP(2005)12/FINAL). Disponível em: <http://ideas.repec.org/p/oec/traaab/21-en.html>. Acesso em: 19 abr. 2008.

ORGANIZAÇÃO MUNDIAL DO COMÉRCIO - OMC. Trade facilitation. Disponível em: <http://www.wto.org/english/tratop_e/tradfa_e/tradfa_e. htm >. Acesso em: 14 mai. 2010.

PESTANA, M.H.; GAGEIRO, J.N. Análise de dados para ciências sociais: complementaridade do SPSS. 4. ed.Lisboa: Edições Sílabo, 2005. 690 p.

PORTO, P.C.S.; CANUTO, O. Uma avaliação dos impactos regionais do Mercosul usando dados em painel. Pesquisa e Planejamento Econômico, Rio de Janeiro, v. 34, no 3, p. 465-484, dez. 2004. 
PORTUGAL-PEREZ, A.; WILSON, J.S. Export performance and trade facilitation reform: hard and soft infrastructure. Washington, 2010. (World Bank Policy Research Working Paper, 5261).

SADIKOV, A.M. Border and behind-the-border trade barriers and country exports. Washington, 2007. 32 p. (IMF Working Paper, 07/292). Disponível em: $<$ http://ssrn.com/abstract=1079220 >. Acesso em: 11 fev. 2008.

SANTOS SILVA, J.M.C.; TENREYRO S. The log of gravity. The Review of Economics and Statistics, Cambridge, v. 88, n. 4, 2006. Disponível em:<http://ideas.repec. org/a/tpr/restat/v88y2006i4p641-658.html> . Acesso em: 28 nov. 2008.

SHEPHERD, B.; WILSON, J.S. Trade facilitation in ASEAN member countries: measuring progress and assessing priorities. Washington, 2008.(World Bank Policy Research Working Paper, 4615). Disponível em: < http://econ.worldbank. org/external/default/main?pagePK=64165259\&piPK $=64165421 \&$ theSitePK $=46$ 9372\&menuPK $=64166093 \&$ entityID $=000158349 \_20080506092605>$. Acesso em: 18 jun. 2008.

SILIVERSTOVS, B.; SCHUMACHER, D. Estimating gravity equations: to log or not to log? Berlin, 2007.42 p. (Discussion Papers of DIW Berlin, 739). Disponível em: <http://ideas.repec.org/p/diw/diwwpp/dp739.html>. Acesso em: 28 nov. 2008.

SOUZA, M.J.P; BURNQUIST, H.L. Facilitação de comércio e impactos sobre o comércio bilateral. Estudos Econômicos, Vol.41 No.1 São Paulo Jan./Mar. 2011. p.91-118.

- Importância das exigências técnicas à exportação de empresas brasileiras. In: CONGRESSO DA SOCIEDADE BRASILEIRA DE ECONOMIA E SOCIOLOGIA RURAL, 46., 2008, Rio Branco. Anais... Brasília: SOBER, 2008. 1 CD-ROM.

SOUZA, M.J.P. Impactos da facilitação sobre os fluxos de comércio internacional: evidências do modelo gravitacional. 2009. 110 p. Tese (Doutorado em Economia Aplicada) - Escola Superior de Agricultura "Luiz de Queiroz", Universidade de São Paulo, Piracicaba, 2009.

TINBERGEN, J. Shaping the world economy: suggestions for an international economic policy. New York: Twentieth Century Fund, 1962. 330 p.

UNITED NATIONS CONFERENCE ON TRADE AND DEVELOPMENT UNCTAD. Electronic commerce and developing countries: a computable general equilibrium analysis. Genebra, 2001. Disponível em: $<$ http://r0.unctad.org/ ecommerce/docs/edr01_en.htm>. Acesso em: 5 mai. 2009.

WESTERLUND, J.; WILHELMSSON, F. Estimating gravity model without gravity using panel data. 2006. Disponível em: < http://www.nek.lu.se/NEKJWE/research. htm >. Acesso em: 28 nov. 2008. 
WILSON, J.S.; MANN, C.L.; OTSUKI, T. Trade facilitation and economic development: measuring the impact.Washington, 2003.(World Bank Policy Research Working Paper, 2988). Disponível em: <http://ssrn.com/abstract $=636350>$. Acesso em: 12 mar. 2009.

. Assessing the potential benefit of trade facilitation: a global perspective. Washington, 2004.(World Bank Policy Research Working Paper, 3224). Disponível em: <http://econ.worldbank.org/external/default/main?pagePK= 64165259\&piPK=64165421\&theSitePK=469372\&menuPK=64216926\&entity $\mathrm{ID}=000009486 \_20040603162036 \mathrm{http}: / / \mathrm{ssrn} . \mathrm{com} /$ abstract $=610266>$. Acesso em: 12 mar. 2009.

WILSON, N. Examining the effect of certain customs and administrative procedures on trade. Overcoming border bottlenecks: the costs and benefits of trade facilitation. Paris, 2009. (OECD Trade Policy Studies). Disponível em: <http://www. oecdbookshop.org >. Acesso em: 10 mar. 2010. 
